\title{
A GOVERNAÇÃO DE TERRITÓRIOS METROPOLITANOS. CONTEXTO INSTITUCIONAL E DE PLANEAMENTO NAS REGIÕES DE MADRID, BARCELONA, PARIS E LISBOA
}

\section{THE REgIONAL METROPOLITAN GOVERNANCE. INSTITUTIONAL MARK AND PLANNING IN MADRID, BARCELONA, PARIS AND LISBON}

\author{
José Miguel Fernández Güell ${ }^{1}$
}

Rui Florentino ${ }^{2}$

\begin{abstract}
Resumo
Em resposta aos desafios atuais de muitas grandes cidades, o contexto institucional e o planeamento territorial formam dimensões para melhorar a governação metropolitana. No quadro das regiões capitais do sudoeste europeu, quais poderão ser as inovações e diferenças nos seus modelos e processos em curso? Este artigo propõe uma investigação aplicada para apresentar a análise da governação metropolitana. Através do método de estudos de caso em perspectiva comparada, vários elementos e entrevistas são ponderados qualitativamente nas regiões de Madrid, Barcelona, Paris e Lisboa.

As conclusões encontram uma tendência para o equilíbrio entre os esforços dessas duas dimensões da governação territorial metropolitana, não impedindo registrar os seus diferentes percursos: por exemplo lle-de-France desenvolveu boas iniciativas em matéria de planeamento, que então pedem alguns ajustamentos no quadro político, enquanto Madrid teve "menos actividade" nos últimos anos, em resultado da sua grande estabilidade institucional. A região de Lisboa permanece talvez numa "posição intermédia", com uma dinâmica de evolução pouco previsível. Mas de acordo com este argumento, admite-se que os seus processos podem levar a melhorias graduais no sistema de governação, com o seu próprio percurso, implementando acções que devem respeitar, em particular, a geografia do território.
\end{abstract}

Palavras-chave: Governação, Território, Metrópoles.

\section{Abstract}

Addressing the running challenges of several greater cities, the institutional mark and regional planning are dimensions for improving metropolitan governance. Regarding the southwest European capital regions, what can be the innovations and differences in their currently processes and models? This paper proposes an applied framework to present the metropolitan governance analysis. Through a comparative case study methodology, various elements and interviews are qualitatively measured in the regions of Madrid, Barcelona, Paris and Lisbon.

The conclusions find a tendency to balance between the efforts on those two regional metropolitan governance dimensions, which does not prevent to register their different paths: for example lle-de-France has developed good initiatives in terms of planning, which then require some adjustments in the political mark, while Madrid had in recent years "less activity", in result of his institutional stability. The Lisbon region maybe stays in an "intermediate position" with a dynamic evolution that is difficult to predict. But according to that argument, it's possible to admit that his processes can gradually lead to small improvements in his governance system, with his own path, implementing actions that must respect, in particularly, the geography of the territory.

Keywords: Governance, Territory, Metropolis.

\footnotetext{
1 Departamento de Urbanística y Ordenación del Territorio, Escuela Técnica Superior de Arquitectura, Universidad Politécnica de Madrid, España. E-mail: josemiguelfernandez@upm.es

2 Escola Superior Gallaecia e Centro de Sistemas Urbanos e Regionais, CESUR - CEris, Instituto Superior Técnico, Universidade de Lisboa, Portugal. E-mail: ruiflorentino@esg.pt
} 


\section{INTRODUÇÃO}

O estudo dos aglomerados urbanos tem revelado um aumento progressivo da escala de análise, orientada para as áreas e regiões metropolitanas, considerando que actualmente mais de metade da população vive a menos de uma hora de uma grande cidade (World Bank, 2008). Reconhece-se portanto que, desde diferentes perspectivas académicas e profissionais, cresce o interesse sobre o urbanismo e o ordenamento do território, disciplinas que no contexto europeu enfrentam hoje importantes desafios, em particular devido a dois fenómenos complementares: por um lado a fragmentação dos poderes, e a consequente necessidade de melhorar a coordenação entre as entidades públicas (Salet, Thornley e Kreukels, 2003); e, por outro, a crescente competitividade entre as grandes cidades, enquanto actores colectivos que podem chegar a superar o papel dos Estados, como líderes da economia à escala global (Jouve e Lefèvre, 2002, ou Clark, 2007). As capitais europeias constituem-se actualmente como uma "marca" cultural exportável, com departamentos de promoção global, atentos aos rankings das consultoras. Compreende-se então que, para enfrentar tais desafios, assiste-se hoje a uma mudança conceptual no processo de gestão activa dos territórios metropolitanos. Ultrapassada que está uma administração pública "verticalmente estruturada", importa que os governos sejam capazes de se adaptar facilmente à mudança, com processos mais horizontais de participação e cooperação (Sigmund, 2003), que resultem de uma partilha variável de decisões e responsabilidades.

De forma simples, pode dizer-se que a nova "modalidade" de governo assume desde logo a vantagem da colaboração com os cidadãos e agentes socioeconómicos. A partir de um esquema em triângulo, em anterior artigo foram apresentados os elementos principais de governabilidade territorial, agrupados em três níveis: na base, os meios (a tecnologia, os recursos e o capital social), suportando o desenvolvimento de funções - os processos operativos e as competências organizativas, que por sua vez poderão permitir a implementação de uma estratégia de desenvolvimento (Fernández Güell, 2006). Em sintonia, mas através de um desenho circular, Mireia Belil (2003) justificou que o êxito da estratégia territorial é influenciado por competências (administrativas), conhecimentos e, obviamente, pela democracia.

Mais do que um ordenamento que desenha o território, tratase de criar um dispositivo informativo e de coordenação, onde resultam essenciais 3 elementos: «a capacidade» - informação e conhecimentos técnicos, "a competência» - poder e instrumentos para actuar e, finalmente, «a democracia» - que permita o debate e a participação.

Nesse mesmo sentido, de compreender a capacidade de governação, Heinelt e Kubler (2005) estudaram a presença de várias tipologias nas entidades territoriais dos países europeus: 
desde o sistema britânico, com uma maior experiência na adaptação à "dimensão" metropolitana, passando pelos modelos alemão e escandinavo, também descentralizados, embora politicamente mais fortes na escala regional, até aos países do Sul, talvez com excessivo peso na administração local, mas que podem configurar soluções organizativas relativamente inovadoras. Em qualquer caso, defende-se que:

Conseguir estratégias territoriais integradas, ao nível da região urbana, depende, não somente de ter as políticas e os instrumentos necessários, mas também da existência de um contexto institucional adequado. (Healey, 1996).

Os factores que condicionam o governo dos territórios metropolitanos parecem assim resultar de dois conjuntos de elementos, um relacionado com o enquadramento das políticas, que se pode designar de contexto institucional, e outro onde se incluem as práticas territoriais, relativas aos processos operativos de planeamento (Florentino, 2008). Na primeira dimensão situam-se então as competências do quadro normativo, os recursos humanos, económicos e tecnológicos e a liderança política e democrática. Já o segundo conjunto, de carácter técnico, integra a participação e o capital social, a estratégia territorial e ainda a cooperação para a implantação de projectos relevantes. Pretende-se neste artigo contribuir para o estudo das interrelações entre estas duas dimensões da governação, com base em estudos de caso: as regiões metropolitanas de Lisboa, Madrid, Barcelona e Paris. De seguida apresenta-se o modelo de análise, que permitiu o desenvolvimento desta investigação.

\section{MODELO CONCEPTUAL DE ANÁLISE}

Para concretizar este objectivo, de analisar as capacidades de governação dos territórios metropolitanos, importa precisar, em primeiro lugar, quais os processos que constituem o objecto de estudo. Conforme se verificou, é possível identificar factores ligados a uma dimensão institucional do governo, a par de outros, mais integrados nas práticas operativas de ordenamento. Esta diferença conceptual permite desenhar um modelo de análise que relaciona as duas principais dimensões da governação, em que os processos de competências, legislação territorial, recursos, democracia e liderança apresentam sobretudo reformas no contexto de governo, enquanto que os processos de participação, criação de mais capital social, estratégia territorial e colaboração para a implantação de projectos podem resultar inovadores, na perspectiva das técnicas de planeamento. 
Figura 1 - Posições teóricas das regiões, em função dos seus processos em curso, de reformas no contexto institucional e inovação em práticas operativas de ordenamento do território.

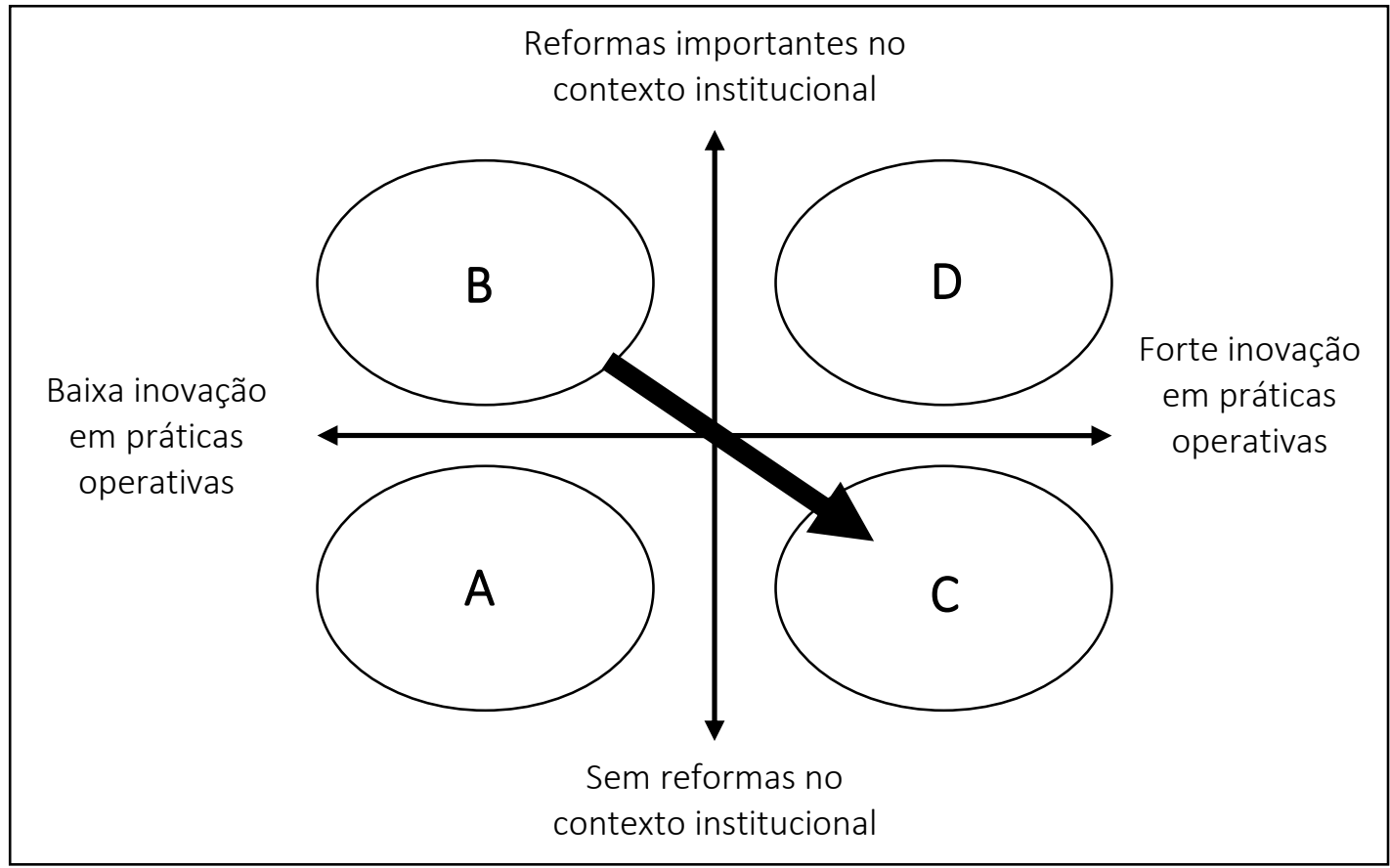

A figura 1 apresenta o modelo de análise sobre os processos de governação, demonstrando que a relação entre as reformas de contexto, por um lado, e a inovação das práticas, por outro, oferece quatro posições diferenciadas:

1. A ausência de dinâmicas de mudança, tanto no quadro institucional de governo, como nos processos operativos de ordenamento, pode caracterizar as regiões mais estabilizadas, que se situam na posição A;

2. Na posição B, encontram-se as regiões que apostam realmente por mudanças estruturais, como por exemplo nas competências legais, nos recursos e nas formas de eleição dos poderes territoriais, ainda que mantenham as suas práticas habituais nos processos operativos de ordenamento;

3. A posição $C$ destaca as regiões que, apesar dos problemas, mantêm o quadro institucional, enquanto se esforçam claramente por inovar as práticas de planeamento através de uma maior participação e da criação de capital social, com acordos de colaboração sobre planos estratégicos e projectos territoriais que potenciem o desenvolvimento metropolitano e regional;

4. E finalmente a posição D identifica as regiões que se mostram mais capazes de gerir mudanças relevantes, seja no contexto institucional ou nos processos operativos de governação territorial. 
A hipótese inicialmente apontada sugere que as actuais respostas aos desafios de governação das regiões metropolitanas se afastam da posição $B$ e se dirigem para a posição $C$, porque as regiões vão reforçando progressivamente os seus activos nas práticas de ordenamento, superando a necessidade de alterar, previamente, o quadro político e institucional, que se encontra mais estabilizado. Trata-se de sublinhar o que alguns autores designam de:

falácia institucional", dada a insistência da "necessidade de
dispor de novos mecanismos administrativos, exemplo talvez
da crença partilhada pelos assessores de que a melhor maneira
de resolver os problemas públicos consiste em acrescentar
novas entidades à máquina administrativa (...) Conforme essa
falácia institucional, a agregação de novas estruturas serve de
substituto à autêntica reforma (Hebbert, 2000).

Para reflectir sobre este argumento, realizou-se uma discussão dos processos actualmente em curso, em diferentes estudos de caso, com base em 3 instrumentos de contraste da informação: i) fontes documentais (análises de outros trabalhos, leis, planos, etc.), ii) entrevistas a peritos e iii) experiência directa (participação dos autores em propostas de planeamento metropolitano, como o Plano Regional de Ordenamento do Território da Área Metropolitana de Lisboa, entre 2009 e 2010, e os estudos para o Plano Regional de Estratégia Territorial de Madrid).

Considerado a dimensão institucional da governação metropolitana, detalham-se agora os desafios actualmente mais relevantes, como a simplificação normativa do sistema de planeamento, a descentralização de competências da administração (ou da entidade regional), a perda de algumas competências locais para o âmbito metropolitano, a melhoria dos recursos humanos para a coordenação a essa escala, a legitimidade democrática e o reforço da liderança política, igualmente a nível supramunicipal, que resumidamente se apresentam nos próximos parágrafos.

Começando pela simplificação do quadro jurídico do sistema de planeamento territorial, esta será sem dúvida um processo útil, porque a acumulação de legislação, de objectivos especiais e por vezes contraditórios, dificulta a aplicação dos planos, contribuindo para que a disciplina de urbanismo seja um amplo campo de interpretação normativa, embora de consequências nefastas para a governação metropolitana;

De forma análoga, a descentralização de algumas competências da administração central para o nível metropolitano explica-se pelo princípio de subsidiariedade, que significa que a decisão deve exercer-se ao nível mais próximo dos cidadãos, que possa resolver com eficácia o problema em análise. Não faz pois sentido que o Estado mantenha responsabilidades que melhor se podem gerir por entidades locais, que também melhor conhecem os problemas territoriais.

Em sentido contrário a essa descentralização de competências, pode ser igualmente útil a passagem de certas responsabilidades municipais para uma escala metropolitana. De facto, uma 
excessiva fragmentação de diferentes estratégias territoriais também não facilita o ordenamento, que de forma integrada surge a partir de uma perspectiva abrangente, reforçando o mesmo princípio de eficiência.

Por seu lado, mais recursos para a coordenação técnica metropolitana justificam-se pela inter-relação entre os problemas destas regiões, com especial relevância para a articulação entre o planeamento urbano e as redes viárias e de transporte público. Um gabinete tecnicamente capaz de coordenar a implementação dos planos de nível superior e informar ainda as propostas municipais deverá dispor dos recursos económicos e tecnológicos adequados, que lhe permitam perseguir os objectivos de ordenamento.

Por último, a legitimidade democrática de um governo de carácter metropolitano é um processo elementar para atingir políticas públicas com essa escala, reconhecido inclusive pelos municípios destas regiões. De facto, os cidadãos que se deslocam diariamente por todo esse território, para desenvolver as suas actividades quotidianas, deveriam de poder eleger um governo de âmbito metropolitano, porque essa é a escala geográfica que influência a sua qualidade de vida, para além do concelho onde têm residência oficial.

$\mathrm{Na}$ perspectiva de melhorar a capacidade de governação territorial, há assim a oportunidade para a construção de uma liderança de dimensão metropolitana. Ainda que tal possa constituir uma ameaça política para o Estado e a cidade capital, seria uma boa notícia para o ordenamento destas regiões, se enquadrada, naturalmente, num sistema de poderes limitados e partilhados.

De acordo com o quadro administrativo das entidades territoriais existentes em cada região, as possíveis reformas deste contexto condicionam de facto os processos operativos de ordenamento territorial, mas não se podem sobrevalorizar em excesso, já que por certo se encontram esforços de inovação em qualquer modelo institucional.

Em complemento às mudanças estruturais, interessa portanto analisar igualmente as práticas de planeamento, perceber como se aplicam, ou se, pelo contrário, constituem processos actualmente paralisados. As acções mais relevantes neste âmbito serão as iniciativas empresariais no ordenamento, a participação dos cidadãos no planeamento, a integração de estratégias sectoriais, a avaliação dos efeitos dos planos territoriais e de diferentes alternativas na preparação de projectos e ainda a cooperação voluntária entre os municípios na sua execução, constituindo variáveis que se apresentam seguidamente.

A criação de mais capital social para o ordenamento do território supõe que os agentes socioeconómicos estejam dispostos a tomar iniciativas, influenciando as decisões, porque na 
economia é hoje tão importante a boa conectividade e o ambiente urbano envolvente como as condições de vida em toda a região metropolitana.

Em paralelo, cresce a participação da sociedade civil, através de fóruns profissionais e outros colectivos mais informais. As ONG's de vocação ambiental são actores relevantes nos processos de organização urbana e territorial, mas também desde outras perspectivas vem aumentando a confiança dos cidadãos para intervir, o que estimula a informação para o debate público das propostas.

A estratégia territorial deverá portanto integrar as preocupações dos agentes socioeconómicos e cidadãos, respondendo aos desafios colocados para atingir o desenvolvimento. Necessita-se assim de um plano territorial de síntese e coerente (aqui como na terminologia francesa), que será tanto mais governável quanto maior for a inclusão o equilíbrio dos objectivos sectoriais, que os outros departamentos públicos têm previsto para essa mesma região.

Na habitual sequência de fases planeamento, de informação, análise e proposta, com frequência não se desenvolvem os passos seguintes, de avaliação e monitorização. De facto, as melhores práticas demonstram que a avaliação das estratégias territoriais é uma condição básica para a sua posterior revisão, promovendo desse modo, igualmente, a adesão aos novos objectivos.

Por seu lado a avaliação de diferentes alternativas nos projectos de forte impacto metropolitano, como seja a construção de infraestruturas de transporte, é uma prática frequente dos governos, cumprindo requisitos legais e de qualidade ambiental. No entanto, dessa apreciação resultam por vezes vários conflitos, que um conhecimento técnico mais aprofundado ajuda a clarificar.

Estes processos operativos de governação territorial podem completar-se através da cooperação voluntaria entre as entidades municipais, que oferece ao planeamento um outro sentido, agora de baixo para cima. Com efeito, a implementação de qualquer estratégia metropolitana depende bastante dos acordos entre os municípios vizinhos, para a execução de projectos integrados e complementares.

Propomo-nos assim estudar o modo como estes processos evoluíram recentemente, em diferentes regiões metropolitanas, com o objectivo de explorar os seus "activos" na capacidade de governação.

\section{APLICAÇÃO A ESTUDOS DE CASO}

Apresentam-se de seguida os conhecimentos obtidos sobre a implantação das principais dimensões de governação territorial metropolitana, nas dinâmicas de quatro estudos de caso. A 
leitura de quais os processos em curso permitirá então configurar a posição teórica de cada região no modelo conceptual de análise, antes de se concluir, relativamente ao equilíbrio entre as reformas do contexto institucional e a inovação nas práticas operativas de ordenamento.

$\mathrm{Na}$ análise da implantação recente destes processos, que poderão melhorar as capacidades de governação metropolitana, nota-se que estas regiões aplicam de facto mais variáveis operativas do que reformas de contexto institucional, como se deduz na contabilidade do quadro seguinte, que assinala um maior esforço de inovação nas práticas de ordenamento. Num primeiro momento, isso parece confirmar o argumento da hipótese provisória lançada na Figura 1, que sugeria que as regiões apostam actualmente mais por esses processos operativos, de acordo com a experiência acumulada. No entanto, um olhar mais atento demonstra que essa diferença só ocorre na região de Paris (lle-de-France), que tem realmente em curso a sua atenção nas práticas de planeamento, enquanto que nas alterações estruturais mantém "apenas" a legitimidade democrática regional e supra-municipal (departamentos).

Quadro 1 - Processos actualmente em curso em quatro regiões metropolitanas: Madrid (M), Barcelona (B), Paris (P) e Lisboa (L).

\begin{tabular}{|c|}
\hline Reformas do contexto institucional \\
\hline Simplificação normativa do sistema de planeamento territorial \\
\hline Descentralização de competências do Estado ou governo regional \\
\hline Perda de competências municipais para uma escala metropolitana \\
\hline Recursos técnicos para a coordenação metropolitana \\
\hline Legitimidade democrática supra-municipal \\
\hline Liderança política supra-municipal \\
\hline
\end{tabular}

\begin{tabular}{|c|}
\hline Inovação nas práticas territoriais \\
\hline Iniciativas empresariais para o ordenamento do território \\
\hline Participação dos cidadãos nas estratégias de ordenamento \\
\hline Integração de estratégias sectoriais no planeamento \\
\hline Avaliação contínua dos planos territoriais \\
\hline Avaliação de alternativas técnicas nos principais projectos \\
\hline Cooperação voluntária entre os municípios \\
\hline
\end{tabular}

Ao contrário, nos outros casos registra-se um equilíbrio, apesar de que existem também processos operativos em qualquer região, cuja inovação pode efectivamente resultar de um 
esforço progressivo na melhoria das práticas territoriais. Neste âmbito, destacam-se de facto as variáveis que mostram alguma continuidade no tempo e se consideram relevantes para a governação metropolitana, tais como as iniciativas dos agentes socioeconómicos na "Comunidade" de Madrid, a cooperação voluntária entre municípios na região de Barcelona, a avaliação integrada de alternativas técnicas em lle-de-France e a participação dos cidadãos nos planos de ordenamento, parcialmente em curso no caso de Lisboa.

Figura 2 - Dinâmica de governação territorial na região de Madrid (M).

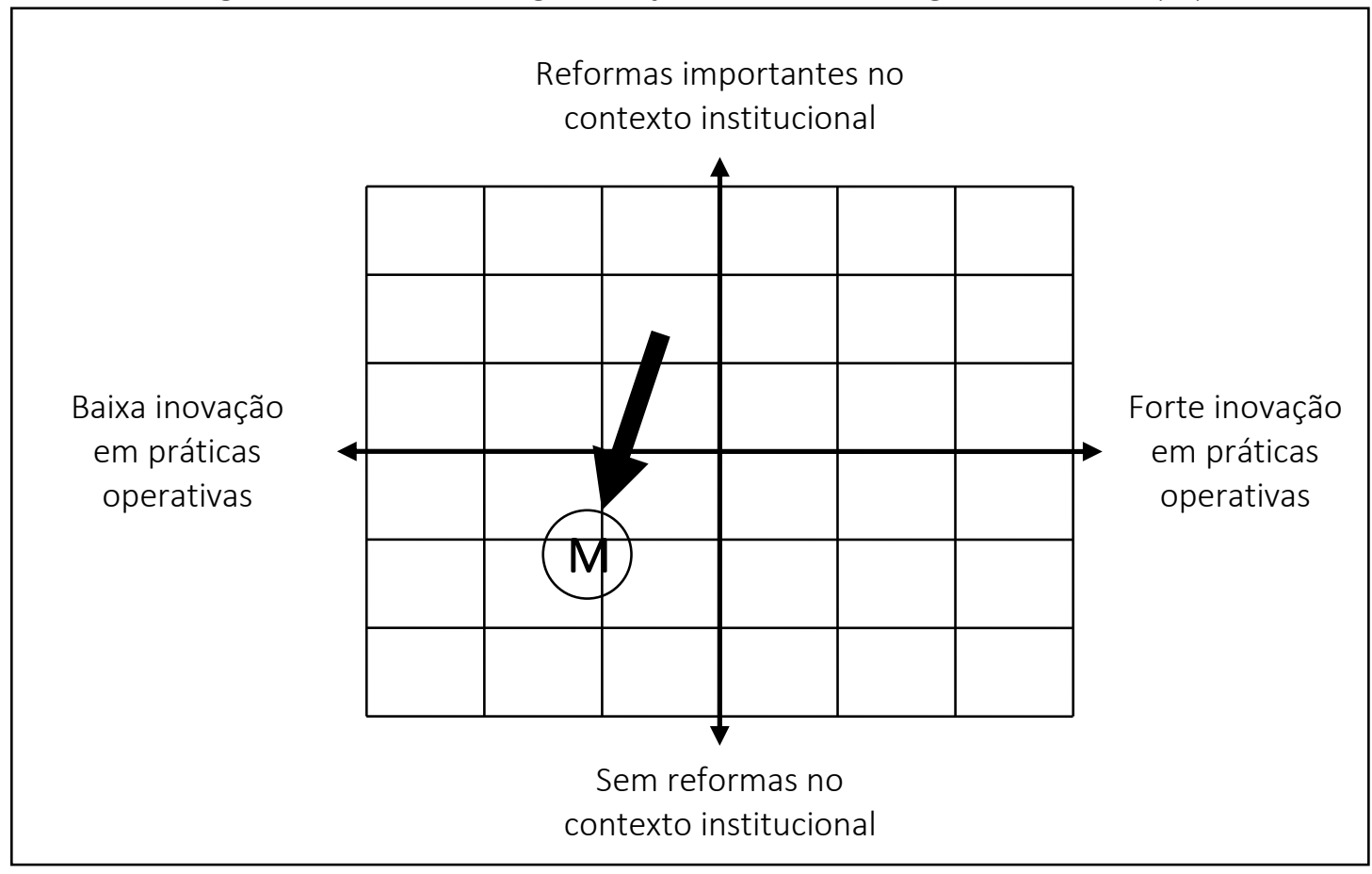

Ao começar por Madrid, não há dúvida de que se encontra com relativamente poucos processos actualmente em curso, no quadro conceptual de análise. O sentido da seta mostra a possível dinâmica de evolução recente, porque às primeiras acções do governo regional - como a gestão das Directrizes de Ordenamento e a inovação no enquadramento legislativo de 1984 - não correspondeu o planeamento compreensivo do território, apesar das bases para o Plano Regional de Estratégia Territorial de 1996. A liderança política da Comunidad de Madrid esteve mais atenta ao investimento em grandes infraestruturas de mobilidade, que proporcionaram um crescimento inédito da urbanização. É verdade que as condições de contexto são aqui bastante favoráveis, o que não diminui a capacidade de governação, mas seria futurologia prever neste caso o sentido da tendência de evolução nos próximos anos. Reconhece-se contudo que as reflexões disciplinares mais recentes poderão talvez corrigir os problemas criados com essa demissão de um planeamento territorial integrado. 
Como activo relevante de Madrid, destacam-se as iniciativas da sociedade civil nos processos de ordenamento, em linha com a procura de uma maior participação de agentes e cidadãos, presente já desde a transição democrática, no final dos anos 70 , no enfrentamento dos municípios com o novo poder regional. Recentemente, mesmo os sindicatos têm reforçado a atenção sobre o território, reconhecendo que:

a cidade, como espaço físico e social e os processos para a sua construção (como, onde, quem e para quem se constrói), são matérias que dizem respeito, plenamente, à reflexão de um sindicato, que não pode, não deve, manter-se à margem do debate urbanístico. Em última instancia, a Cidade (...), deve entender-se como um 'salário social', que vem completar, complementar e enriquecer o salário directo. ${ }^{3}$

Por outro lado, desde 1981 que a "Comissão de Urbanismo da Confederação Empresarial de Madrid" vem desenvolvendo um trabalho contínuo para promover o ordenamento, também a escala metropolitana, em particular sobre as possibilidades de implementação de actividades económicas. Nos últimos anos tem publicado vários relatórios que oferecem uma visão mais integrada e pedagógica do planeamento: normativa, paisagem urbana, eficiência energética e propostas para o Plano Regional de Estratégia Territorial da Comunidade de Madrid.

Figura 3 - Dinâmica de governação territorial da região de Barcelona (B).

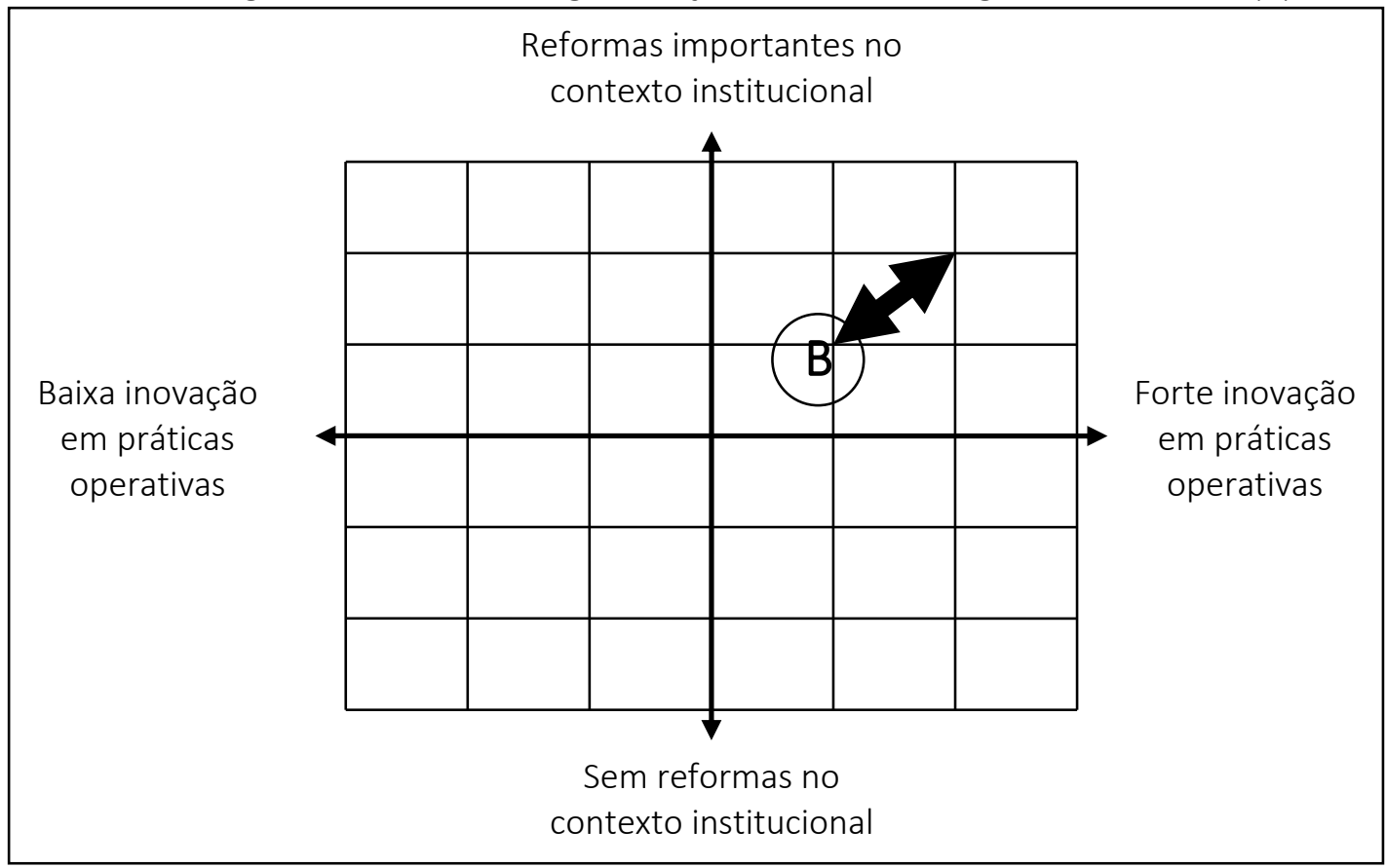

\footnotetext{
${ }^{3}$ Introdução de Rodolfo Benito Valenciano aos artículos publicados no livro "Otro Urbanismo es Posible. Siete Miradas sobre Madrid" (Ediciones GPS Madrid, 2007).
} 
Já nas outras regiões, sim que é possível interpretar uma possível dinâmica de evolução a curto prazo. Em Barcelona, reconhece-se que "sempre" houve processos em curso para melhorar a governação metropolitana. Nos próximos anos, os esforços colectivos terão por certo continuidade, nas reformas de descentralização do governo regional, nas acções do novo Consorcio:

Área Metropolitana de Barcelona" e também em práticas que promovem o trabalho em rede com os actores sociais e económicos, justificando-se a tendência de evolução positiva (Figura 3), dado que neste caso não se terá "que partir do zero, porque a estrutura de governo territorial já está levantada (Echániz, 2002).

Neste caso, percebe-se que a colaboração voluntária entre os municípios é um processo progressivo de acções notáveis no planeamento estratégico e territorial. Mas mesmo antes da sua estabilização institucional no actual regime jurídico de Consórcio, a Mancomunidade obteve grande experiência na implantação de projectos, dotando-se de capacidades técnicas para executar obras de infraestruturas, habitação e espaços públicos, em benefício de toda a região. Criou-se em 1992 o Instituto Metropolitano de Promoção do Solo e Gestão Patrimonial, que construiu habitação social em operações integradas com os municípios, através de tipologias adequadas às jovens famílias, que não encontravam esse tipo de oferta na promoção convencional. Para tal contribuiu a política de aquisição de solos, em convénios com os concelhos periféricos, reforçando-se a confiança do trabalho de colaboração.

Os processos em curso na região de Paris revelam, por seu lado, uma aposta considerável na inovação das práticas de ordenamento, frente à aparente estabilidade do contexto institucional. Contudo, é precisamente no quadro da relação entre poderes onde se jogam as principais mudanças, intervindo a administração central e a cidade capital, pela liderança do projecto metropolitano. De acordo com Ariane Azéma (2009), "esta evolução será tributária de equilíbrios políticos, de negociações institucionais, incluindo o Estado, de dinâmicas de projectos e ainda da sua visibilidade internacional. Ela será além disso condicionada por uma revisão fiscal y financeira. Mas não poderá ser desligada de um sentimento de pertença e identidade, componentes igualmente decisivos para a governabilidade e la organização regional." Ora isto indica, portanto, igualmente uma dinâmica de possíveis alterações estruturais, que em conjunto com a implementação das estratégias territoriais e intermunicipais (dos Esquemas Director e de Coerência), serão os processos mais relevantes para melhorar as capacidades de governação. 
Figura 4 - Dinâmica de governação territorial da região de Paris (P).

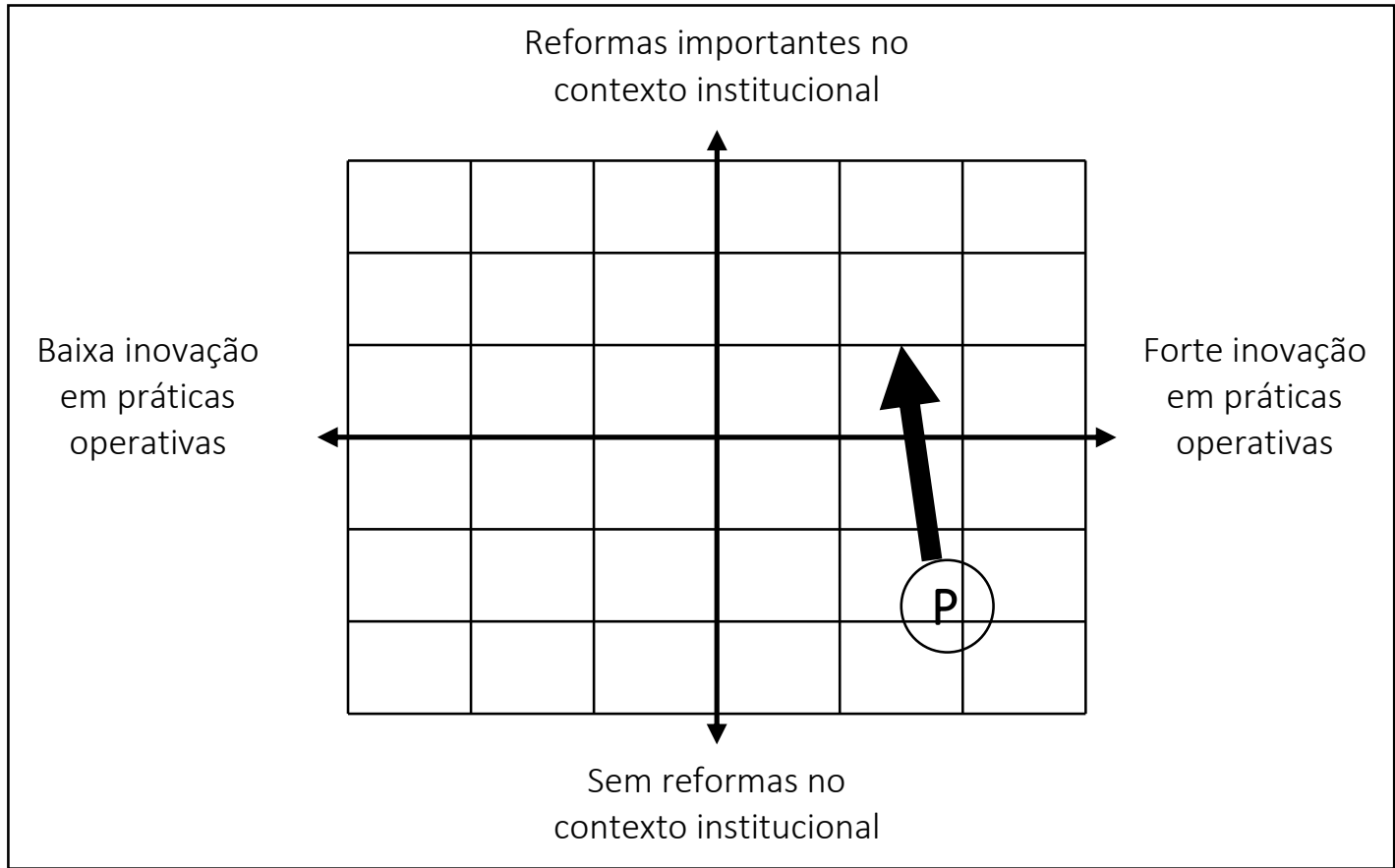

A avaliação de alternativas nos grandes projectos territoriais é um processo em curso nas quatro regiões, mas em Paris adquire uma escala mais ambiciosa. Em 2008 o governo central lançou uma consulta internacional para debater novas ideias sobre o desenvolvimento da região capital. As propostas mantêm-se de certa forma válidas, já que o objectivo não era selecionar um projecto, mas abrir a discussão metropolitana a toda a sociedade, com peritos de vários países. Todo o território regional esteve assim em estudo, não apenas uma infraestrutura relevante, mas sim a reflexão em torno de diferentes modelos conceptuais. ${ }^{4}$ Por certo este processo não foi inocente e contribuiu para reforçar a intervenção do "governo Sarkozy" na Grand Paris, que dispôs de uma Secretaria de Estado para a promoção da sua competitividade internacional. Perante as opções municipais e do Conselho Regional de Ile-de-France, é visível portanto uma política da administração central para a região metropolitana, que se justificará porque:

O Estado não se pode desinteressar dos territórios que produzem cerca de um terço da riqueza nacional. Ainda que as entidades locais sejam naturalmente gestoras, elas não

\footnotetext{
${ }^{4}$ O Esquema Director de Ordenamento Territorial, apresentado pelo Conselho Regional também em 2008, completa-se assim com outros projectos, como reconheceram as equipas internacionais convidadas. Da consulta resultaram propostas de diferentes objectivos e escalas, desde a conexão a Le Havre, formando um território metropolitano linear até ao mar, aos conceitos de novas infraestruturas e centralidades. Entre as várias ideias, três temas foram recorrentes: a ligação do ordenamento aos transportes, o reforço das identidades urbanas e a preocupação ecológica (Liotard, 2009). Por exemplo o Groupe Descartes apresentou três metas sugestivas: mais $20 \mathrm{~m} 2$ por habitação, menos $30 \mathrm{~m}$. de mobilidade diária e menos 2 graus de temperatura.
} 
dispõem, de momento, das instâncias de coordenação necessárias (Sarkozy, 2010).

Esta posição confirma-se numa leitura histórica, já que de algum modo todos os líderes franceses quiseram deixar a sua marca na cidade, como ocorreu também com François Mitterrand nas décadas de 80 e 90.

Figura 5 - Dinâmica de governação territorial da região de Lisboa (L).

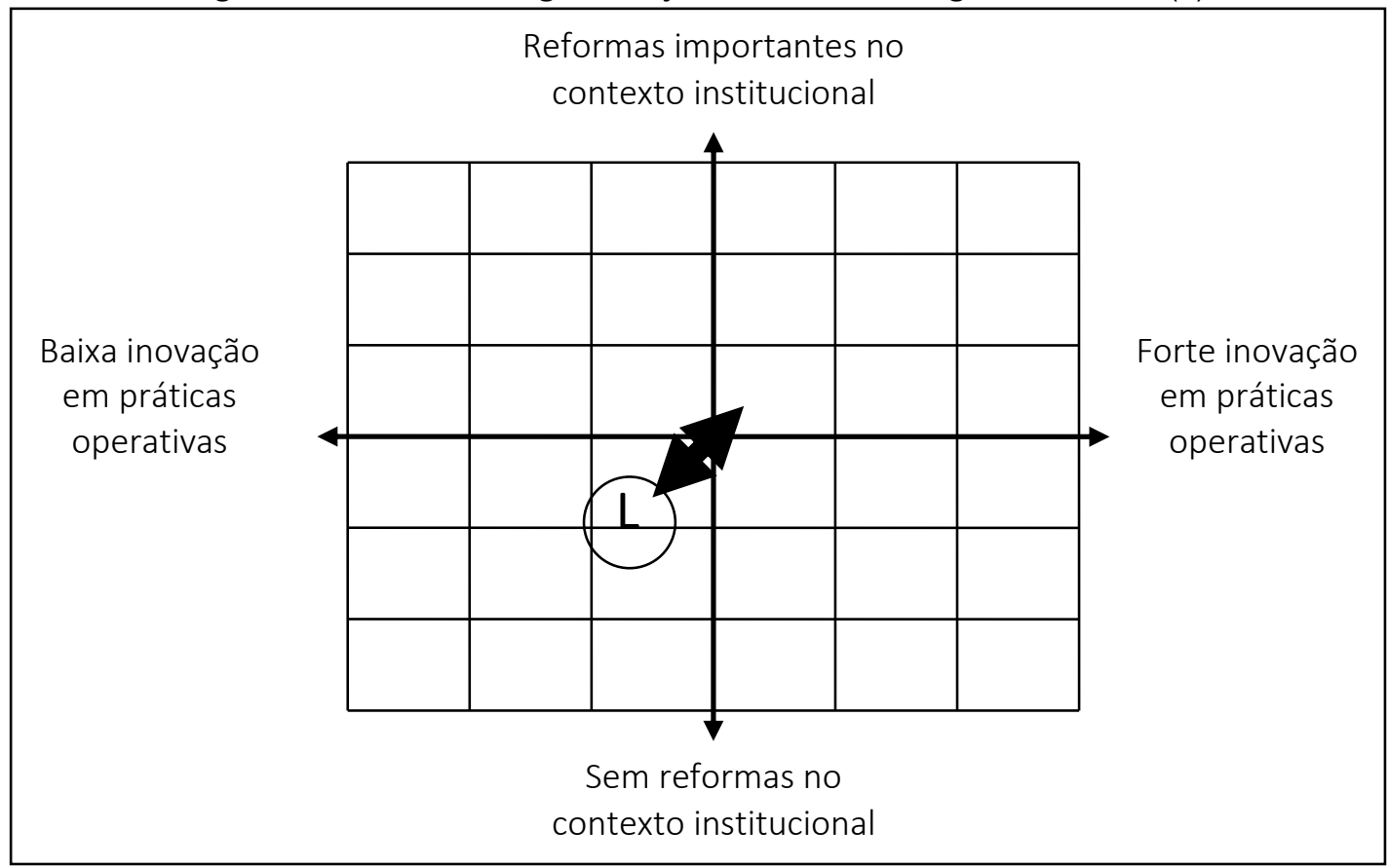

Já na região de Lisboa, reconhecendo-se embora a necessidade de alterações efectivas em matéria de competências, recursos e organização regulamentar, existem também oportunidades para melhorar as práticas territoriais. No entanto, tudo parece depender de uma eventual reforma de descentralização administrativa do Estado e da construção de uma liderança técnica e política de dimensão metropolitana, tal como se argumentou anteriormente (Florentino, 2011). Mas a sua posição teórica neste modelo de análise de governação, face aos processos actualmente em curso (Figura 5), revela a mesma incerteza que Madrid.

Um dos processos relevantes são os períodos de participação na preparação dos planos de ordenamento, onde a região adquiriu alguma experiência, sobretudo no âmbito dos trabalhos promovidos pela Comissão de Coordenação e Desenvolvimento Regional, sob a liderança de António Fonseca Ferreira. A nível nacional, em 2006, um exemplo significativo foi a melhoria do Programa Nacional da Política de Ordenamento do Território, após o momento de consulta pública, que se poderá replicar na revisão do planeamento metropolitano.

Em resumo a estes estudos, assinalaram-se os processos actualmente em curso em quatro regiões metropolitanas, notando-se várias diferenças, que não surpreendem considerando 
igualmente as diversas condições geográficas e organizativas. Madrid e Lisboa revelam mais dificuldades no desenvolvimento das capacidades de governação do território metropolitano, enquanto que a reflexão sobre Barcelona e Paris apresenta a evolução de reformas no contexto institucional, a par de um esforço de inovação nas práticas de ordenamento. Estes dados permitem então concluir sobre a dinâmica entre as principais dimensões da governação metropolitana.

\section{DISCUSSÃO DE RESULTADOS}

Através da análise de contraste entre os processos em implantação e aqueles que serão mais relevantes em cada região, destacaram-se quatro activos, que mesmo em diferente grau de execução demonstram poder gerar efeitos positivos, de melhoria das capacidades de governação metropolitana. Esses processos são as iniciativas dos agentes no planeamento territorial da região de Madrid, a cooperação voluntária entre municípios em Barcelona, a avaliação de alternativas de desenvolvimento em Paris e a participação pública nas estratégias de ordenamento, ainda timidamente em Lisboa. Todos eles pertencem aos elementos relacionados com uma dimensão mais operativa da governação territorial, o que sugeriu que se poderia confirmar a hipótese provisória de que existem boas práticas em cada região, às quais se deve dar especial atenção, para inovar a partir da experiência acumulada, em vez de repensar sempre o contexto institucional onde esses processos se inserem.

Figura 6 - Dinâmicas de governação territorial em perspectiva comparada.

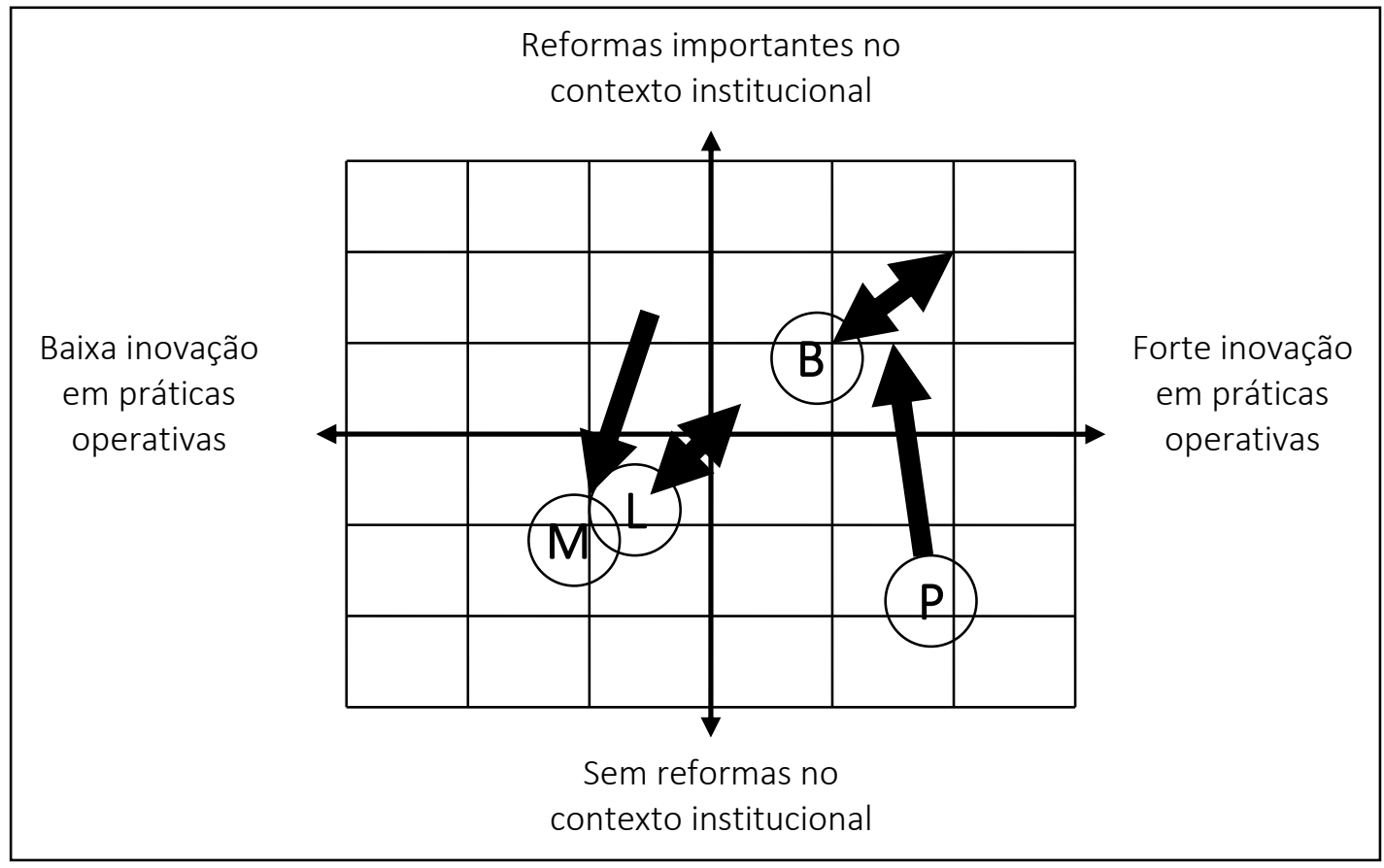


Esta ideia confirma-se, de facto, mas o conhecimento mais aprofundado sobre estas regiões permite ajustar essa conclusão, devido a três razões. Em primeiro lugar, nos casos de Madrid e Lisboa, os efeitos positivos de tais processos podem entender-se como uma resposta dos agentes a acções em falta ou que não se desenvolvem da melhor maneira: em Madrid é a ausência de um quadro integrado de planeamento que assinala a importância das iniciativas da sociedade civil, estando por verificar se essa situação apenas se resolverá com a mudança política no poder regional; e em Lisboa os momentos de discussão pública dos planos são úteis para consolidar as propostas, que possivelmente deveriam estar melhor preparadas, funcionando assim a normativa para um nível intermédio de coordenação.

Uma segunda precisão é que estão também em curso importantes reformas do contexto institucional, que serão igualmente relevantes na capacidade de governação metropolitana destas regiões, como a liderança política supra-municipal em Barcelona ou a descentralização de competências e a simplificação do sistema de planeamento no caso de Lisboa. Isso justifica-se pela natureza técnico-política destes processos de governo e ordenamento do território, já que se registra uma tendência para que desde a orientação política se pense que os planos podem resolver qualquer problema e que, por seu lado, desde a perspectiva profissional se peçam com frequência alterações do enquadramento institucional. ${ }^{5}$

A terceira evidência é que ao observar as dinâmicas de governação no modelo conceptual de análise, em nenhum caso se dá a evolução de que as regiões preferem actualmente apostar pelas suas práticas potencialmente inovadoras nos processos de ordenamento, superando a necessidade de rever o quadro organizativo e institucional. É certo que se poderá situar a região de Paris nessa posição relativa, talvez pela sua maior experiência de planeamento territorial, mas a dinâmica de evolução indica que estão também em curso relevantes "lutas de poder" no espaço metropolitano: a cidade capital, as "inter-comunalidades", o conselho regional e a administração central. Neste caso, dá-se por assumido que a fragmentação de competências é positiva, permitindo pelo contrário alcançar consensos efectivos. Já em Madrid e Lisboa, os processos em desenvolvimento são hoje mais limitados, possivelmente porque também as condições estruturais não favorecem a inovação, "tese" que a região de Barcelona confirma pelo "quadrante positivo", uma vez que a implantação de melhores práticas de planeamento estimula as reformas de

\footnotetext{
${ }^{5}$ Os técnicos habitualmente comentam que os problemas do planeamento territorial só se resolvem através de novas competências ou outras entidades administrativas (essa "falácia institucional" a que se referia Michael Hebbert). Mas os resultados deste estudo indicam que, em sentido contrário, são precisamente necessários bons processos operativos em curso, para motivar tais reformas estruturais.
} 
contexto (Figura 6). As tendências de evolução, seja em Paris ou em Barcelona, revelam portanto uma relação de duplo sentido, de duas dimensões que se alimentam de forma recíproca. ${ }^{6}$

Temos pois agora os conhecimentos suficientes para poder concluir, porque se por um lado se confirmam inovações progressivas sobre a experiência acumulada, em participação e capital social, estratégia territorial e cooperação voluntária em projectos, reconhece-se que, em simultâneo, são também relevantes as mudanças estruturais no contexto institucional de governo, em matérias de competências, recursos e liderança. Trata-se portanto de processos dinâmicos, que se vão influenciando uns a outros, em contínua evolução, o que afasta assim a utilidade de se configurar "a priori" um quadro de responsabilidades teoricamente perfeito. A contribuição que resulta desta análise é que as capacidades de governação metropolitana podem melhorar com a abertura de cada região para que a implantação deste tipo de processos seja feita com suficiente flexibilidade, já que o desenvolvimento de um dos activos produz mudanças noutros e assim sucessivamente. Verifica-se então essa mútua influência, o que não impede que se registem trajectórias indirectas (figura 7) - na região de Paris, as práticas territoriais em curso requerem mudanças de enquadramento, enquanto que Madrid, por seu lado, teve uma menor actividade, possivelmente em resultado de uma grande estabilidade institucional, ao longo dos últimos anos.

Figura 7 - Tendência geral de evolução do sistema de governação territorial metropolitana.

\footnotetext{
${ }^{6}$ Leitura que se potencia ainda na região de Barcelona, considerando a sua forte tradição de planeamento à escala metropolitana, que se manifesta tanto no esforço político para melhorar as condições de governação da "Mancomunidade de municípios", como na promoção das "funções quotidianas", através das entidades gestoras de ambiente, transporte, habitação social e espaço público, além da visão partilhada da estratégia territorial, com o governo regional.
} 


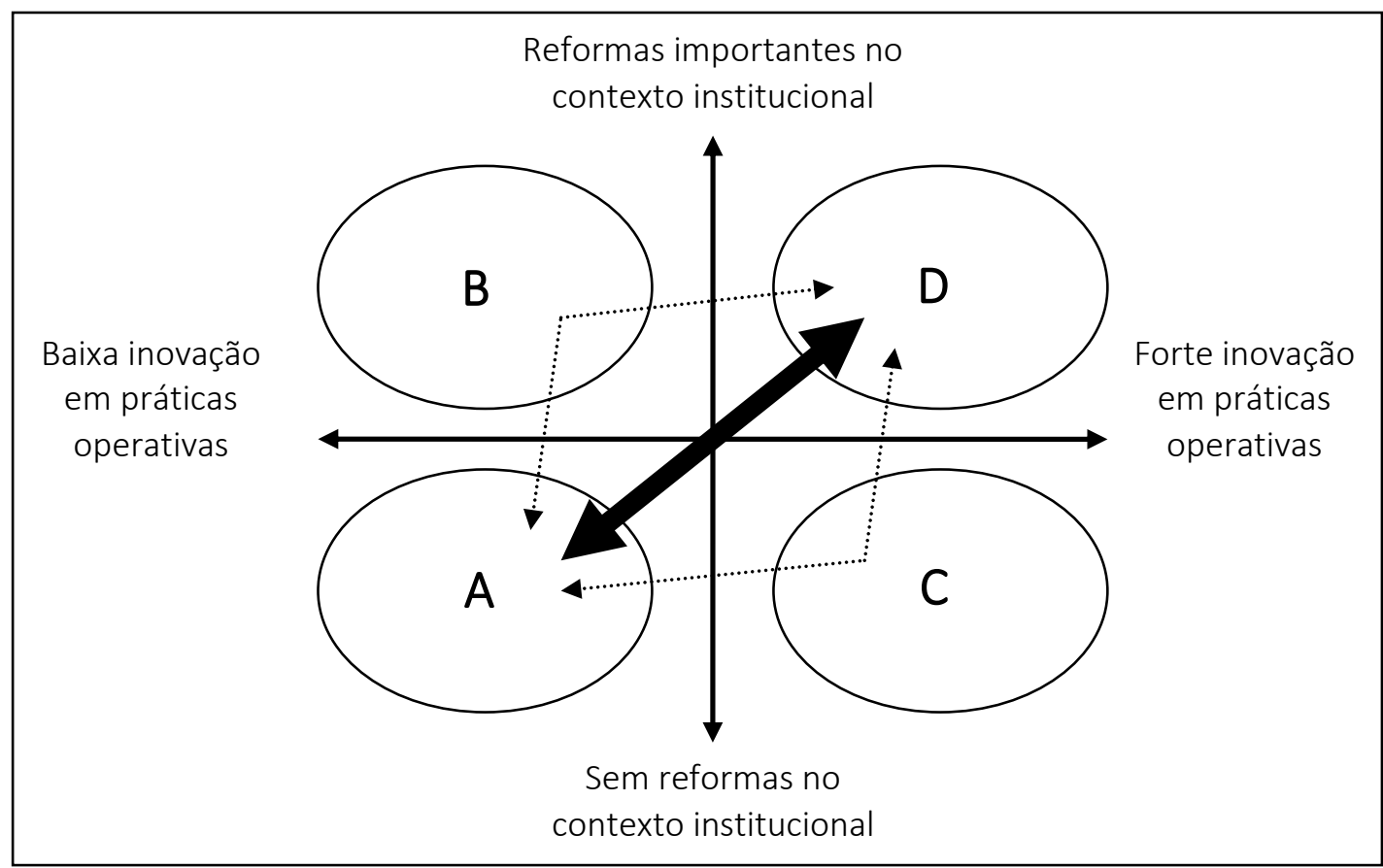

No modelo conceptual de análise, que relaciona as duas principais dimensões da governação metropolitana, a tendência que se verifica não é portanto do campo B para o C, mas antes uma dinâmica de movimento entre $\mathrm{A}$ e $\mathrm{D}$, porque à medida que aumentam as capacidades colocam-se também novos desafios, que pedem respostas específicas. Ainda que por momentos a região se concentre num destes processos em particular, isso logo motivará acções sequenciais em cadeia. Se era pois óbvio que as reformas do contexto institucional convocam mudanças nas práticas de ordenamento, constata-se que, sobretudo pelos casos de Barcelona e Paris, em sentido contrário os processos operativos provocam igualmente alterações estruturais, o que demonstra a sua correspondente influência nas competências, nos recursos e na liderança, já que esse enquadramento também não permanece estável.

\section{REFERÊNCIAS BIBLIOGRÁFICAS}

AZEMA, Ariane (2009); 'Métropole francilienne: une gouvernance à la croisée du local' in Les Cahiers no 151. Paris: Institut d'Aménagement et d'Urbanisme de la Région lle-de-France.

BELIL, Mireia (2003); 'La ordenación de las áreas metropolitanas europeas' in Font, Antonio (coord.): Planeamiento Urbanístico. De la controversia a la renovación. Barcelona: Diputación de Barcelona.

CLARK, George (2007); 'The Business of Cities' in The Vital City, European Urban Research Association Conference, Glasgow.

COMISSÃO DE COORDENAÇÃO E DESENVOLVIMENTO REGIONAL DE LISBOA E VALE DO TEJO; (2010) Proposta de Plano Regional de Ordenamento do Território da Área Metropolitana de Lisboa. 
ORTIZ, Pedro (coord.); Comunidad De Madrid (1996); Bases del Plan Regional de Estrategia Territorial. Coordenação técnica de Madrid: Consejería de Obras Públicas, Urbanismo y Transportes.

GASPAR, Jorge (coord.); Direcção-Geral Do Ordenamento Do Território E Desenvolvimento Urbano (2007) Programa Nacional da Política de Ordenamento do Território. Lisboa: Ministério do Ambiente, do Ordenamento do Território e do Desenvolvimento Regional.

ECHÁNIZ, Juan (2002) 'Un sistema local para el gobierno del territorio en la sociedad de las redes: el caso de Cataluña' in Subirats, Joan (coord.): Redes, territorios y gobierno. Nuevas respuestas locales a los retos de la globalización. Barcelona: Diputación de Barcelona.

ENGUITA, Abel (2007) 'La incidencia previsible de la futura Ley del Suelo Estatal en el Urbanismo Español' in Revista de la Confederación Empresarial Independiente de Madrid no 111. Madrid.

EZQUIAGA, José María (2006) 'Geografía mutante. El crecimiento desbordado de la capital' in Arquitectura Viva no 107-108. Madrid.

FERNÁNDEZ GÜELL, José Miguel (2006); Planificación Estratégica de Ciudades. Nuevos Instrumentos y Procesos. Barcelona: Editorial Reverté.

FLORENTINO, Rui (2011); Procesos innovadores de gobierno y ordenación del territorio. La región metropolitana de Lisboa en Perspectiva Comparada. Tese de Doutoramento. DUyOT-ETSA, Universidad Politécnica de Madrid.

(2008) 'Parámetros de gobernabilidad territorial metropolitana' in Cadernos Metrópole no 20. São Paulo: EDUC.

FUNDACIÓN SINDICAL DE ESTUDIOS Y COMISIONES OBRERAS DE MADRID (coord.) (2007) Otro Urbanismo es Posible. Siete miradas sobre Madrid. Madrid: Ediciones GPS.

Carreras, Josep (coord.); Generalitat de Catalunya (2008), Pla Territorial Metropolità de Barcelona. Barcelona: Departament de Política Territorial i Obres Públiques.

HEALEY, Patsy (1996) 'Las fortalezas y debilidades de la aproximación comprensiva a la planificación regional: la experiencia Británica' in La ciudad global ¿Cómo gestionarla? Madrid: Consejería de Medioambiente y Ordenación del Territorio de la Comunidad de Madrid.

HEBBERT, Michael (2000) 'El Grupo de Trabajo - Task Force - y el nuevo enfoque del urbanismo británico' in Urban no 4. Madrid: DUyOT-ESTA, UPM.

HEINELT, Hubert; KUBLER, Daniel (eds) (2005) Metropolitan Governance. Capacity, Democracy and the Dynamics of Place. London: Rouledge.

INSTITUT D’AMÉNAGEMENT ET D’URBANISME DE ILE-DE-FRANCE (2008), Schéma Directeur de la Région lle-de-France.

JOUVE, Bernard; LEFÈVRE, Christian (2002) Métropoles ingouvernables. Les villes européennes entre la globalisation et décentralisation. Paris: Elsevier. 
LIOTARD, Martine; DUGUET, Anca; FOUCHIER, Vincent; TRICAUD, Pierre-Marie (2009) 'Grand Pari(s), acquis d'une consultation hybride' in Les Cahiers no 151. Paris: Institut d'Aménagement et d'Urbanisme de la Région lle-de-France.

MONZÓN, Andrés (2007) 'Madrid: el transporte' in Regiones Capitales. Planificación y Desarrollo Sostenible de las Regiones Capitales Europeas. Madrid: Consejería de Medioambiente y Ordenación del Territorio de la Comunidad de Madrid.

ROGERS, Richard (coord.) (1999) Towards an Urban Renaissance. Final Report of the Urban Task Force. London: Spon Press.

ROJAS, Eduardo; CUADRADO-ROURA, Juan R.; FERNÁNDEZ GÜELL, José Miguel (eds) (2005) Gobernar las metrópolis. Washington: Banco Interamericano de Desarrollo.

SALET, William; THORNLEY, Andy; KREUKELS, Anton (eds) (2003) Metropolitan Governance and Spatial Planning. Comparative Case Studies of European City-Regions. London: Spon Press.

SARKOZY, Nicolas (2010) 'Le Grand Paris', entrevista de Fréderic Gilli e Cyrille Poy, in L'Architecture d'Aujourd'hui no 376. Paris.

SIGMUND, Anne Marie (2003) 'En route vers las citoyenneté européenne' in A face oculta da governança: cidadania, administração pública e sociedade. Lisboa: Instituto Nacional de Administração.

WORLD BANK (2008); World development Report 2009: Reshaping Economic Geography. Washington: World Bank Publicatons.

Trabalho enviado em 15 de fevereiro de 2015.

Aceito em 11 de abril de 2015. 